\title{
Abordagem da dislexia na região de Vitória da Conquista na Bahia: uma análise sob a perspectiva neurocientífica
}

\author{
Dyslexia approach in Vitória da Conquista region in Bahia: \\ a review in the neuroscientific perspective \\ Ronei Guaresi \\ Catiane Silva Santos \\ Márcia Mangueira \\ Universidade Estadual do Sudoeste da Bahia - Bahia - Brasil
}

$\diamond$

Resumo: A dislexia é uma patologia no aprendizado da leitura e da escrita, cujas dificuldades não se justificam por ambiente social ou familiar desfavorecido, por algum déficit sensorial, por método de ensino ineficiente ou por baixos índices nas escalas de inteligência. Neste estudo realizou-se uma análise das condições estruturais e humanas na região de Vitória da Conquista na Bahia para a abordagem dessa dificuldade de aprendizado por meio de entrevistas a docentes atuantes no Ensino Fundamental I, entrevistas a estudantes matriculados no curso de Pedagogia em disciplinas de últimos semestres e levantamento da matriz curricular desse curso na universidade que oferece esse curso na cidade. De maneira geral, observamos neste estudo que, embora a literatura científica aponte para incidência de 5 a $10 \%$ de aprendizes, não há entendimento e preparação para administração da dificuldade de aprendizado da leitura e da escrita conhecida como dislexia: a) na matriz curricular consta a disciplina Dificuldade de aprendizagem como optativa; b) docentes e estudantes afirmaram não se sentirem preparados para a administração dessa dificuldade de aprendizado e c) os estudantes não dispõem de estrutura satisfatória para eventuais intervenções

Palavras-chave: Dislexia; Dificuldade de aprendizagem; Ensino

\begin{abstract}
Dyslexia is an abnormality in the reading and writing learning, whose difficulties are not justified by disadvantaged social or family environment for some sensory deficit, by inefficient method of education or low levels in the intelligence scales. This study conducted an analysis of the structural and human conditions in the region of Vitória da Conquista in Bahia for the approach of this learning difficulties through interviews with teachers acting in elementary school, interviews with students enrolled in pedagogy courses in the disciplines of last semesters and lifting the curriculum of this course in the university offering this course in the city. Overall, this study observed that although the scientific literature point to incidence $5-10 \%$ of apprentices, there is no understanding and preparation for administration of learning difficulties in reading and writing known as dyslexia: a) the curriculum consists Difficulty learning the discipline as an optional; b) teachers and students said they did not feel prepared for the administration of this difficulty learning and c) the students not have satisfactory structure for possible interventions.
\end{abstract}

Keywords: Dyslexia; Learning difficulties; Teaching 
Salvo algumas exceções, o ensino no Brasil anda em descompasso com as descobertas das ciências. As avaliações oficiais, ano após ano, mostram a precariedade do ensino brasileiro ${ }^{1}$. O salto de qualidade do ensino passa necessariamente pela aproximação entre as descobertas científicas e o que se faz em sala de aula, tanto sob o ponto de vista de conteúdo quanto de opções pedagógicas e metodológicas.

No que diz respeito às descobertas científicas sobre o cérebro humano, nas últimas décadas, deixamos de simplesmente fazer hipóteses para acompanhar o movimento das ativações neuronais em cérebro in vivo. Claro está que o nosso conhecimento sobre os engendramentos do cérebro humano estão em sua gênese, contudo, lançam luzes, por exemplo, sobre alguns dos problemas de aprendizagem da escrita. Segundo John Gabrieli (2009), em publicação na Revista Science, as descobertas recentes sobre a dislexia provocaram uma nova sinergia entre educação e as ciências cognitivas. $\mathrm{O}$ que as pesquisas têm mostrado é que, embora ainda controversa, é possível ao professor intervir e minimizar as dificuldades de aprendizado.

Diante desse cenário, de um lado as avaliações oficiais mostrando índices preocupantes de compreensão leitora e, de outro, os conhecimentos advindos das neurociências sobre as dificuldades de aprendizagem, neste estudo analisamos as condições estruturais e humanas em Vitória da Conquista na Bahia para a condução pedagógica da dificuldade de aprendizado conhecida como dislexia. Para isso entrevistamos 32 docentes atuantes no Ensino Fundamental I, 15 estudantes matriculados no curso de Pedagogia em disciplinas de último semestre, e, ainda, realizamos um levantamento da matriz curricular das universidades que oferecem cursos de Pedagogia nessa cidade. A questão central explorada neste estudo, portanto, trata da preparação dos profissionais em educação (incluem-se aqui os em fase final de formação acadêmica) para a condução pedagógica da dificuldade de aprendizado conhecida como dislexia.

\section{Dislexia - conceito e incidência}

Analisando pelas suas causas, a dislexia é uma dificuldade desproporcional de aprendizagem da leitura, que não se pode explicar nem por um retardo mental ou por um déficit sensorial, nem por um ambiente social ou familiar desfavorecido. Cabe a ressalva, contudo, que

\footnotetext{
Para maiores informações ver o Programa Internacional de Avaliação de Estudantes, o PISA (Programme for International Student Assessment) no endereço $<$ http://www.oecd.org/pisa/ $>$.

Aqui no Brasil o SAEB (Sistema de Avaliação da Educação Básica) no endereço $<$ http://portal.inep.gov.br/saeb $>$. Ainda o indicador IDEB (Índice de desenvolvimento da Educação Básica) no endereço <http:// ideb.inep.gov.br/>.
}

nem todos os maus leitores são disléxicos, equívoco frequente entre os educadores. Essas variáveis têm de serem descartadas para um diagnóstico de dislexia. Caso um aprendiz tenha um retardo mental, por exemplo, a dificuldade acentuada de aprendizado da leitura provavelmente se deve a esse déficit cognitivo, não sendo possível chegar a um diagnóstico de dislexia.

$\mathrm{Na}$ definição do diagnóstico dessa dificuldade de aprendizado é difícil colocar uma fronteira que separe, de modo não arbitrário, as crianças normais das disléxicas, pois depende de certa interpretação de um limite entre o que é típico e o que é atípico. Entre as crianças francesas, a fronteira definida aponta para 6 e $8 \%$ de crianças em idade de alfabetização com dislexia (DEHAENE, 2012). No continuum que representa o aprendizado da leitura há os aprendizes que não apresentam dificuldades, os que aprendem com certa dificuldade e entre 5 e $10 \%$ que passarão por grandes dificuldades para o aprendizado da leitura e da escrita. Isso é um fenômeno universal que acompanha a apropriação desse engenhoso e complexo fenômeno cultural (RAMUS, 2003).

$\mathrm{O}$ que a ciência tem mostrado é que há forte indício genético envolvido no diagnóstico da dislexia. Entre irmãos, se um dos membros for acometido de dislexia, a probabilidade de que um de seus parentes diretos sofra da mesma dificuldade é da ordem de $50 \%$ (PAULESU et al., 2001). Apesar de ter forte base genética, não é resultado de alteração monogênica, isto é, ligada a um só gene. Vários são os fatores de risco e vários são os genes que, uma vez alterados, contribuem para dificultar o aprendizado da leitura. A leitura proficiente depende de porção de associações sinápticas das células nervosas que, segundo francês Stanislas Dehaene (2012), tem de serem recicladas para o processamento da leitura já que esta é fenômeno cultural recente na história da evolução do homem.

Dada a complexidade de associações inerentes à linguagem e dada a demanda de processamento cognitivo que o aprendizado da leitura requer, qualquer alteração na mecânica neuronal representa enorme sofrimento para alguns aprendizes da modalidade escrita da língua. Daí se observa nesses aprendizes a dificuldade de automatizar diferentes processos que subjazem a leitura proficiente.

\section{Tratamento cognitivo dos fonemas}

A comunidade científica concorda hoje em pensar que os problemas de conversão dos próprios grafemasfonemas provêm deste aspecto fundamental: a maioria das crianças disléxicas sofre de distúrbios no tratamento dos fonemas e da consciência fonêmica (LIBERMAN, SHANKWEILER, ORLANDO, HARRIS e BERTI, 1971; BRADLEY e BRYANT, 1978; FISCHER, LIBERMAN e 
SHANKWEILER,1978; BRADLEY e BRYANT, 1983). Essa conclusão, aparentemente improvável, fundamenta-se, contudo, sobre várias constatações convergentes. Relacionando-as às crianças cujo desenvolvimento é normal, as crianças disléxicas apresentam diferenças muito salientes nos testes de consciência fonêmica que avaliam a sensibilidade às rimas, à segmentação em fonemas, ou à recombinação dos sons da fala. Muitos estudos colocam, por certo, um problema de circularidade: na medida em que a consciência fonêmica em si desenvolve-se com a aprendizagem da leitura e do princípio alfabético, torna-se bem difícil separar as causas das consequências. Afinal, as crianças se saem mal na leitura porque não manipulam bem os fonemas ou, ao inverso, saem-se mal na consciência fonêmica porque ainda não receberam os benefícios da alfabetização? Um círculo vicioso parece fechar-se em torno das crianças atingidas pela dislexia. Algumas pesquisas sugerem elementos que superam essa circularidade e outros estudos indicam que, desde muito cedo, há elementos em competências fonológicas que permitem antecipar escores ulteriores da leitura (MURPHY e SCHOCHAT, 2009). As crianças disléxicas parecem sofrer acima de tudo de uma representação imperfeita dos fonemas de sua língua, que introduz uma imprecisão na representação das palavras faladas e atrapalha seu emparelhamento com os signos escritos.

Nos aprendizes com essa dificuldade de aprendizado, a percepção categorial dos sons da fala está frequentemente alterada, ou seja, as crianças apresentam dificuldades em detectar a minúscula diferença temporal que distingue $b a$ de $p a$, particularmente na presença de ruído (BREIER et al., 2003; BREIER, FLETCHER, DENTON e GRAY, 2004). A percepção dos estímulos rápidos pode ser fortemente anormal e se correlacionar estreitamente com os escores na leitura (AHISSAR, PROTOPAPAS, REID e MEZENICH, 2000; TEMPLE et al.; 2000; BREIER, GRAY, FLETCHER, FOORMAN e KLAAS, 2002).

A percepção visual da ordem temporal se apresenta alterada em muitos aprendizes acometidos com essa anormalidade, dentre outros aspectos, também observados. Outros estudos mostram que déficits visuais mais fundamentais também são observados na percepção do movimento ou do contraste (EDEN et al.; 1996; DEMB, BOYNTON e HEEGER, 1997; DEMB, BOYNTON, BEST e HEEGER, 1998).

Diversas outras explicações para as perturbações da leitura foram pesquisadas, não só do cerebelo, que seria responsável pela automatização das aprendizagens (NICOLSON, FAWCETT e DEAN, 2001), como a que causa uma desorganização dos neurônios da via "magnocelular", que veicula as informações temporais rápidas, tanto visuais quanto auditivas (GALLABURDA e LIVINGSTONE, 1993; DEMB et al., 1997; DEMB et al., 1998; DEMB, BOYNTON e HEEGER, 1998; STEIN, 2001). Segundo essas hipóteses, o núcleo do déficit na dislexia ultrapassaria muito o simples tratamento fonológico: o distúrbio de leitura não seria senão a árvore que esconde a floresta dos déficits de automatização motriz ou de percepção dos estímulos rápidos. Franck Ramus e seus colaboradores afirmam que não é raro que crianças disléxicas sofram de déficits concomitantes das funções motrizes, visuais ou auditivas. Esses pesquisadores não negam que uma minoria de disléxicos (talvez um quarto) apresente um déficit visual acentuado sem perturbação fonológica evidente. Existem casos atestados nos quais a causa da dislexia se situa bem no nível visual (RAMUS et al., 2003; VALDOIS, BOSSE e TAINTURIER, 2004).

Parece prudente, como indiretamente já foi exposto, considerar o problema em toda sua complexidade, sem querer necessariamente reduzi-lo a uma única causa. $\mathrm{Na}$ interface entre natureza e cultura, entre biológico e ambiente, nossa capacidade de ler resulta de um complexo emaranhado de variáveis, no qual um bom ensino é tão primordial quanto a presença prévia de processadores neuronais visuais e fonológicos corretamente interconectados. As pesquisas atuais sinalizam que a hipótese segundo a qual o cérebro das crianças disléxicas sofre de uma dupla fragilidade, onde confluem as vias de reconhecimento visual invariante e o tratamento fonológico da língua falada, parece, pois, particularmente plausível (DEHAENE, 2012). Exames de imagem sustentam que é nesse nível, na representação das conexões do lobo temporal, que se situam com frequência alterações que provavelmente são a causa da dificuldade do aprendizado da leitura.

Os estudos de imagem cerebral da dislexia mostram uma subativação na região temporal posterior esquerda. Essa observação ocorre não somente no adulto, mas também na criança de 8 a 12 anos, onde sua amplitude antecipa a severidade das perturbações da leitura. Outra anomalia é, igualmente, frequente: nos disléxicos, o córtex frontal inferior esquerdo (região de Broca) é, com frequência, superativado durante a leitura, ou durante outras tarefas fonológicas, ao que parece, numa tentativa de compensação (SHAYWITZ et al., 2002; McCRORY et al., 2005). Destacam-se no hemisfério esquerdo, duas regiões com subativação no cérebro dos disléxicos: o córtex temporal lateral e uma região temporal mais inferior que pertence à via visual ventral.

Segundo Stanislas Dehaene, citando Silani e sua equipe (2005), com o advento das técnicas de neuroimagens (PET, IRMf, tractografia, etc.) é possível antever dificuldades no aprendizado da leitura, por meio de: a) análise estatística de regiões onde a matéria cinzenta é densa e em outros locais rarefeita; b) análise 
dos aumentos de volume do córtex comparativamente aos padrões de normalidade (SILANI et al., 2005). Ainda sobre a anatomia cerebral dos disléxicos, Albert Galaburga descobriu numerosas "ectopias" (palavra de origem grega que significa que os neurônios não estão em seu lugar) no cérebro do disléxico. No curso da gestação, os neurônios corticais se deslocam a distâncias consideráveis num vasto movimento migratório que os encaminha até a zona germinal em torno dos ventrículos, onde eles se formam por divisão celular, até sua posição final nas diferentes camadas do córtex (GALABURDA, MENARD e ROSEN, 1994).

A divisão e a migração dos neurônios são etapas críticas para a boa formação do cérebro. É nesse momento no curso do desenvolvimento que o cérebro do feto é mais sensível às interferências de agentes patogênicos, tais como o álcool, por exemplo. Nos disléxicos, a migração neuronal parece alterada, ou seja, muitas células nervosas, a julgar pelas camadas corticais mal formadas ou formando microdobras, parecem não terem chegado a seu destino, traindo, dessa forma, a especialização do hemisfério esquerdo para o tratamento da linguagem verbal. Em autópsia, Albert Galaburda descobriu pequenos grupos de neurônios na superfície do córtex, como se eles tivessem ultrapassado sua posição normal (GALABURDA, MENARD e ROSEN, 1994).

\section{Superação da dislexia}

Várias bases de dados genéticos associados à dislexia já foram identificados: cromossomos 1, 2, 3, 6, 16 e 18. Em 2003, uma equipe finlandesa apresentou o gene DYX1C1 no cromossomo 15. Em 2004 e 2005, foram identificados três outros genes de susceptibilidade à dislexia, KIAA0319, DCDC2 (todos os dois no cromossomo 6) e ROBO1 (no cromossomo 3) (GALABURDA et al., 2006). Alterações em quaisquer deles aparentam ser suficientes para significar dificuldade de aprendizado proficiente da leitura. O primeiro deles, por exemplo, atua na migração celular no período intrauterino. Em situação de anormalidade nesse gene, os neurônios não migram para muito longe, o que engendra as ectopias e outros microssulcos característicos do cérebro humano disléxico. Outros genes são implicados: o gene LIS1, por exemplo, trabalha em associação muito estreita com o DYX1C1 e sua perturbação faz com que os hemisférios cerebrais fiquem lisos, sem circunvoluções, e o córtex fica completamente desorganizado. O quarto gene, ROBO1, controla a formação dos filamentos celulares, os dendritos e os axônios, que ligam as metades direita e esquerda do sistema nervoso. Cabe a lembrança de que a pesquisa genética está em curso e teremos, certamente, muitos achados num futuro próximo.
Para Dehaene (2012), vários erros podem ser destacados quando se trata de elementos genéticos. $\mathrm{O}$ primeiro desses erros consiste em associar a biologia a imobilismo, como se o que fosse ditado pelos genes permanecesse gravado por toda vida, sem que pudéssemos mudar coisa alguma. $\mathrm{O}$ segundo erro diz respeito à ideia de que todas as ajudas que prestamos à criança, no curso das sessões de psicopedagogia, de fonoaudiologia, entre outros, não intervêm senão num nível psicológico bem distinto do nível cerebral. Parece-nos interessante conjecturar que há estreita relação entre os genes e as experiências na construção da complexidade cerebral humana, desvelando o equívoco do dualismo platônico ao separar o biológico do social. Esse pesquisador defende que as arborizações neuronais, axônios e dendritos, são modeladas no curso das experiências sensoriais do ambiente físico, social e cultural, estabelecem relação de complementaridade e interdependência entre os genes e as experiências. No atual momento das pesquisas sobre o tema, a origem de dificuldades de aprendizado pode ser alterações genéticas que resultam em má formação do cérebro alterando a dinâmica cognitiva, especialmente do lobo temporal do hemisfério esquerdo. Por outro lado, tal alteração pode ser minimizada por meio de ensino adequado e programas de reeducação, especialmente se há plasticidade neuronal disponível. É oportuno lembrar que quanto mais jovem for o sujeito mais plasticidade dispõe para novos aprendizados e eventuais compensações. No caso de transtornos resultantes de anomalias anatômicas no cérebro, como a dislexia, por exemplo, os estudos neurocientíficos nos sinalizam que programas de treinamento potencializam a plasticidade cerebral e, em alguns casos, recrutam e reciclam outras áreas de células nervosas para compensar déficit de processamento. Para Torgesen (2005), exames de neuroimagens mostram que toda intervenção psicológica repercute nos circuitos neuronais até os níveis celular, sináptico, molecular e vai, mesmo, modificar a expressão dos genes.

A imagem cerebral mostra que a reeducação intensiva produz dois efeitos maiores no cérebro: normalização e compensação (DEHAENE, 2012). No seio das redes típicas de leitura, a atividade se normaliza. Lembremo-nos de que o cérebro disléxico se caracteriza principalmente por uma diminuição da atividade na região temporal esquerda. Depois do treinamento, praticamente todos os estudos com neuroimagens sugerem um nítido ganho de atividade nessa região. Esse aumento explica provavelmente a melhora nos desempenhos fonológicos. Observam-se, também, compensações mais radicais. A atividade cerebral aumenta notadamente nas regiões simétricas do hemisfério direito. Sem dúvida, essas regiões comportam circuitos intactos suficientemente próximos da função requisitada para serem reciclados para leitura. 
É bastante difícil distinguir as causas, as consequências e as simples correlações arroladas na dislexia. Contudo, os distúrbios da percepção dos sons e muito particularmente sua ordem temporal parecem mais fundamentais que os outros na medida em que sua reeducação implica benefícios no domínio da leitura. Uma equipe finlandesa concebeu um software de reeducação em que a criança aprende a jogar um jogo audiovisual em que ouve uma série de sons que variam em altura, duração e intensidade e, ainda, consiste em reconhecer qual forma visual a representa melhor. Depois de sete semanas de treinamento, apenas 10 minutos por dia, duas vezes por semana, as crianças com dificuldade de leitura melhoraram significativamente escores de reconhecimento de palavras (KUJALA et al., 2001). Estudos sobre o aprendizado da música também se correlacionaram positivamente com escores em leitura.

Num cenário que colocamos como ideal, com base na literatura científica sobre o cérebro do disléxico, as instituições de ensino disporiam de ferramentas para antecipar dificuldades no aprendizado da leitura para, a partir do diagnóstico, intervir e aproveitar a plasticidade neuronal da criança. Ainda num cenário ideal, alunos disléxicos disporiam de softwares de treinamento acústico para minimizar a severidade do transtorno. As condições desse cenário ideal garantiriam sucesso no aprendizado da leitura e da escrita para muitos alunos que hoje engrossam a parcela de crianças que não conseguem aprender na idade adequada.

No âmbito pedagógico, atualmente, temos diversas publicações que mesclam teoria e atividades de prevenção e/ou intervenção em casos de dislexia. Teixeira e Martins (2014) propõem, ao valorizar a ludicidade, o uso de jogos e brincadeiras como instrumentos para estimular recursos cognitivos e neuromotores. Nessa perspectiva, as autoras descrevem dezenas de atividades que, quando adequadamente conduzidas, colaboram para que o disléxico supere as dificuldades de aprendizado.

Almeida e Duarte (2012) propõem trinta e oito atividades com o intuito de elevar os níveis de consciência fonológica, variável com algum comprometimento no cérebro disléxico. Segundo elas, as atividades promovem o desenvolvimento fônico e o metafônico, aspectos fundamentais para a leitura e escrita competentes. $\mathrm{Na}$ mesma linha de entendimento, Muszkat e Rizzuti (2012, p. 76) defendem que "é importante que as atividades fônicas e metafonológicas sejam incorporadas, tanto pelos professores na própria sala de aula, quanto pelos profissionais da área psicoeducacional". Segundo os autores, essas "atividades, já disponíveis no Brasil, podem ajudar a prevenir e a intervir em dificuldades de aquisição da linguagem escrita".

Ainda, sobre as discussões sobre consciência, Pereira e Scliar-Cabral (2012), mesmo não sendo uma proposta específica para estudantes com dificuldade de aprendizagem, trazem a consciência linguística (fonológica, morfológica, sintática, léxico-semântica, pragmática, textual) para o ensino da escrita nos anos iniciais (em especial $3^{\circ}$ e $4^{\circ}$ anos). Segundo as autoras, estudos comprovam a validade pedagógica do aprendizado consciente de aspectos da escrita. "Os elementos linguísticos são o ponto de partida para a compreensão, pois a análise linguística do texto alavanca seu entendimento" (PEREIRA e SCLIAR-CABRAL, 2012, p. 49).

Especificamente para casos de dificuldade de aprendizado, Silva e Capellini (2011) propuseram o Programa de Remediação Fonológica: proposta de intervenção fonológica para Dislexia e transtornos de aprendizado. Segundo elas, "escolares que apresentam consciência dos fonemas avançam de forma mais rápida, fácil e produtiva na aprendizagem da leitura e da escrita". Ainda, defendem que disléxicos podem se beneficiar com atividades que envolvam consciência fonológica.

Andrade, Andrade e Capellini (2014) propõem um programa que contempla a identificação de crianças de risco para problemas de aprendizagem e, ainda, para a intervenção precoce. Segundo os autores, é um instrumento para o educador incluir estudantes com dificuldade de aprendizado da leitura e da escrita, adequado à realidade das escolas brasileiras.

\section{As condições da educação brasileira para a abordagem da dislexia: docentes, formação docente, estrutura escolar e matrizes curriculares}

Para fins de avaliação sobre as condições para a administração de questões de dificuldades de aprendizagem como a dislexia, analisamos as condições estruturais e humanas em Vitória da Conquista na Bahia para a administração dessa dificuldade de aprendizado. Para isso entrevistamos docentes atuantes no Ensino Fundamental I e de língua materna na Educação Básica, estudantes matriculados no curso de Pedagogia em disciplinas de último semestre e, ainda, realizamos um levantamento da matriz curricular de disciplinas dos cursos de Pedagogia oferecidos nessa cidade.

Para considerar as questões acima, 32 professores da educação básica foram entrevistados. Os professores atuavam no nível fundamental I (3 primeiros anos escolares) e no ensino de língua materna nos demais níveis da educação básica. Questionados sobre a formação acadêmica, observou-se que $56 \%$ dos professores tinham formação acadêmica para a área em que estavam atuando. Alguns deles estão em processo de formação. Ainda, questionados sobre a abordagem da dislexia nos cursos acadêmicos, nenhum profissional relatou ter tido preparação consistente. 
Frente aos questionamentos acerca do conhecimento do transtorno, $46 \%$ dos professores afirmaram ter algum conhecimento sobre dislexia. Os demais, embora já tivessem ouvido falar, não sabiam dizer do que se tratava. Nenhum profissional afirmou saber muito bem ou não saber da existência dessa dificuldade de aprendizado.

Quando questionados sobre como caracterizava sua segurança para trabalhar adequadamente com um aluno disléxico, nenhum dos professores afirmou se sentir competente o suficiente para trabalhar com crianças com essa dificuldade; $81 \%$ deles afirmaram possuir condições mínimas de dar conta das necessidades desses alunos.

No que tange às condições da escola para o atendimento de crianças com dificuldades de aprendizagem, os professores afirmaram não haver especialistas, senão na sede de coordenação da rede de ensino, contudo, há monitor auxiliar nas classes de alfabetização. Nas escolas não há quem avalie nem quem diagnostique suspeitas de dislexia. O profissional da sede referido pelos professores, quem recebe as crianças com dificuldades escolares, disse desconhecer qualquer caso de dislexia na rede de ensino. Na literatura científica sobre o assunto, a dislexia está descrita como um transtorno universal e que acomete entre 5 e $10 \%$ da população. Logo, a afirmação do especialista sobre desconhecer casos de dislexia é intrigante. Claro está que persistem na literatura científica da área controvérsias acerca dessa dificuldade de aprendizado (MASSI, 2007), além de subjetividade na interpretação do limite entre o aprendizado típico e atípico.

A convergência das respostas dos professores com a literatura ocorreu na questão sobre a importância de identificação e intervenção precoce para o êxito do aprendizado da leitura e da escrita pela criança. Quanto mais cedo for a intervenção mais se aproveita a plasticidade cerebral.

Vitória da Conquista é uma cidade no Sudoeste da Bahia que se coloca como referência econômica, política, social e educação superior. A partir do levantamento das universidades que oferecem o curso de Pedagogia observamos que apenas uma, a Universidade Estadual do Sudoeste da Bahia, a UESB, oferece esse curso em dois diferentes programas: um regular e outro especial. Numa análise do fluxograma do curso regular observamos que há a disciplina Dificuldades de aprendizagem ofertada como optativa e como obrigatória no programa especial. As demais universidades foram desconsideradas por terem número reduzido de matrículas e por serem em forma de Ensino à Distância.

Realizamos, também, 15 entrevistas com estudantes dos últimos semestres de Pedagogia. Observou-se que apenas cinco haviam cursado a disciplina Dificuldade de aprendizagem. A maior parte dos formandos informou que haviam estudado algo sobre a temática na disciplina de Educação Inclusiva. Contudo, todos se mostraram inseguros para identificarem ou realizarem eventuais intervenções em caso de dificuldade de aprendizado de leitura e escrita. Os informantes expuseram, ainda, a configuração essencialmente teórica como a causa da insegurança em administrar tais dificuldades em sala de aula. Diante dos questionamentos sobre quais seriam os principais elementos associados à dislexia, nenhum dos estudantes sinalizou a variável consciência fonológica. Isso mostra, a nosso ver, falta de preparo desses futuros profissionais de ensino sobre o adequado enfrentamento recomendado pela literatura da área para minimizar essa dificuldade acentuada de aprendizado. Nesse sentido, quando questionados sobre os conhecimentos de atividades ou softwares disponíveis para comporem programas de intervenção, afirmaram desconhecê-los.

De acordo com nosso entendimento, a busca de um diagnóstico seguro de dislexia justifica-se apenas para fins acadêmicos. A nosso ver, ao professor, preocupado com o bom andamento pedagógico, de posse do maior repertório possível de conhecimentos sobre essa dificuldade de aprendizado, cabe a implementação de programas de intervenção imediatamente quando da suspeita de dislexia.

\section{Considerações finais}

Diante das variáveis que estão envolvidas na aquisição e no aprendizado da leitura e da escrita, que justificam imensa gama de alunos que chegam a acumular vários anos de estudo sem chegar a níveis satisfatórios de compreensão leitora, pequena parcela certamente deve ser creditada ao aprendizado que podemos considerar de atípico, em especial à dislexia, a qual, a nosso ver, requer condução pedagógica diferenciada e apropriada. Ao que parece, os estudantes acometidos com essa dificuldade específica estão escondidos no contingente de estudantes que acumulam vários anos de estudo sem conseguirem níveis satisfatórios de leitura. Ou seja, parece pertinente conjecturar que essa dificuldade de aprendizado não chama a atenção dos professores, gestores de ensino e especialistas dado o contexto que caracteriza o ensino no Brasil. Ainda no âmbito das conjecturas parece que para a dislexia ganhar evidência e entendida como um desafio que requer enfrentamento pedagógico apropriado, deve-se antes discutir outras questões como métodos de alfabetização, por exemplo.

A dislexia é descrita como uma dificuldade acentuada na aprendizagem da leitura e da escrita. É uma dificuldade de aprendizado de ordem genética que, para parte dos estudos atuais, está associado a um déficit na manipulação mental dos fonemas. $\mathrm{O}$ cérebro das crianças disléxicas apresenta várias anomalias características: a anatomia do 
lobo temporal está desorganizada, sua conectividade está alterada, sua ativação no curso da leitura é insuficiente (DEHAENE, 2012). No que diz respeito ao componente genético, quatro genes de susceptibilidade foram identificados, provavelmente, afetando a migração e o posicionamento dos neurônios do córtex temporal no período intrauterino.

Como se podem observar, vários aspectos estão envolvidos no diagnóstico de dislexia, o que envolve para o seu diagnóstico avaliação multidisciplinar. Embora sob o ponto de vista científico já tenhamos evoluído em conhecimento sobre essa dificuldade específica de aprendizado e já dispormos de publicações, nacionais inclusive, sobre identificação e intervenção em casos de dislexia, os dados levantados para este estudo mostram que, considerando apenas os dados levantados da estrita região do sudoeste baiano: a) as escolas não estão estruturadas nem com aparato físico nem com profissionais especializados para o apoio aos professores em casos de suspeita de dislexia; $b$ ) os profissionais de sala de aula não conhecem suficientemente essa dificuldade a ponto de adequadamente conduzi-la, ou seja, ou não conhecem o que é dislexia ou elegem essa dificuldade como repositório dos fracassos escolares; c) tampouco há formação apropriada em nível de graduação dos futuros profissionais da área de Pedagogia. Embora a matriz curricular do curso contemple a disciplina Dificuldades de aprendizagem, os estudantes que fizeram essa disciplina não se julgam capacitados para a adequada abordagem desse tipo de dificuldade de aprendizado. A nosso ver, é necessário o estabelecimento de políticas específicas e de Estado para garantir que de fato os conhecimentos científicos acumulados cheguem à sala de aula ${ }^{2}$ e dessa forma quebrem o descompasso entre descobertas científicas e ensino no Brasil referido na abertura deste texto.

\section{Referências}

AHISSAR, M.; PROTOPAPAS, A.; REID, M.; MEZENICH, M. M. Auditory processing parallels reading abilities in adults. Proc. Natl Acad Sci USA, v. 97, n. 12, p. 6832-6837, 2000. http://dx.doi. org/10.1073/pnas.97.12.6832

ALMEIDA, E. C. de; DUARTE, P. M. Consciência fonológica: atividades práticas. 2. ed. Rio de Janeiro: Revinter, 2012.

ANDRADE, O. V. C. dos A.; ANDRADE, P. E.; CAPELLINI, S. A. Modelo de resposta à intervenção: como identificar e intervir com crianças de risco para os transtornos de aprendizagem. São José dos Campos, SP: Pulso Editorial, 2014.

\footnotetext{
2 Um exemplo de iniciativa que consideramos louvável é a petição para inclusão do Curso Online de Capacitação de Professores depositado no http://dislexiabrasil.com.br/, no Programa de Formação Continuada de Professores do Estado de Minas Gerais (https://secure.avaaz.org/ po/petition/PROPOSTA_PARA_A_SECRETARIA_ESTADUAL_ DA_EDUCACAO_Consolidacao_do_Dislexia Bras), documento este resultado de discussões do II Fórum Mundial de Dislexia realizado em agosto de 2014 (http://dislexiabrasil.com.br/wdforum2014).
}

BLAU, V.; REITHLER, J.; VAN ATTEVELDT, N.; SEITZ, J.; GERRETSEN, P. GOEBEL, R.; BLOMERT, L. Deviant processing of letters and speech sounds as proximate cause of reading failure: a functional magnetic resonance imaging study of dyslexic children. Brain, v. 133, p. 868-879, 2010. http://dx.doi.org/10.1093/brain/ awp308

BRADLEY, L.; BRYANT, P. E. Categorizing sounds and learning to read: a causal connection. Nature, v. 30, p. 419-421, 1983. http:// dx.doi.org/10.1038/301419a0

BRADLEY, L.; BRYANT, P. E. Difficulties in auditory organization as a possible cause of reading backwardness. Nature, v. 271, p. 746-747, 1978. http://dx.doi.org/10.1038/271746a0

BREIER, J. I.; FLETCHER, J. M.; DENTON, C.; GRAY, L. C. Categorical perception of speech stimuli in children at risk for reading difficulty. J Exp. Child Psycol,v. 88, n. 2, p. 152-170, 2004. http://dx.doi.org/10.1016/j.jecp.2004.03.003

BREIER, J. I.; GRAY, L. C.; FLETCHER, J. M.; FOORMAN, B. e KLAAS, P. Perception of speech and nonspeech stimuli by children with and without reading disability and attention deficit hyperactivity disorder. J. Exp Child Psychol, v. 82, n. 3, p. 226-250, 2002. http://dx.doi.org/10.1016/S0022-0965(02)00005-X

BREIER, J. I.; SIMOS, P. G.; FLETCHER, J. M.; CASTILLO, E. M.; ZHANG, W.; PAPANI-COLAOU, A. C. Abnormal activation of temporoparietal language areas during phonetic analysis in children with dyslexia. Neuropsychology, v. 17, n. 4, p. 610-621, 2003. http:// dx.doi.org/10.1037/0894-4105.17.4.610

DEHAENE, S. Os neurônios da leitura: como a ciência explica a nossa capacidade de ler. Tradução de Leonor Scliar-Cabral. Porto Alegre: Penso, 2012.

DEMB, J. B.; BOYNTON, G. M.; HEEGER, D. J. Brain activity in visual cortex predicts individual differences in reading performance. Proc Natl Acad Sci USA, v. 94, n. 24, p. 13363-13366, 1997. http:/ dx.doi.org/10.1073/pnas.94.24.13363

DEMB, J. B.; BOYNTON, G. M.; BEST, M.; HEEGER, D. J. Psychophysical evidence for a magnocellular pathway deficit in dyslexia. JNeurosci, v. 18, n. 17, p. 6939-6951, 1998. http://dx.doi. org/10.1016/S0042-6989(98)00075-3

EDEN, G. F.; VANMETER, J. W.; RUMSEY, J. M.; MAISOG, J. M.; WOODS, R. P.; ZEFFIRO, T. A. Abnormal processing of visual motion in dyslexia revealed by functional brain imaging. Nature, v. 382, n. 6586, p. 66-69, 1996. http://dx.doi.org/10.1038/ $382066 \mathrm{a} 0$

FAWCETT, A. J.; NICOLSON, R. Naming Speed in Children with Dyslexia. Journal of Learning Disabilities, v. 27, p. 641-646, 1994. http://dx.doi.org/10.1177/002221949402701004

FISCHER, F. W.; LIBERMAN, I. Y.; SHANKWEILER, D. Reading reversals and developmental dyslexia: a further study. Cortex, v. 14, n. 4, p. 496-510, 1978.

GABRIELI, J. Dyslexia: A New Synergy Between Education and Cognitive neuroscience. Science, v. 325, n. 280, p. 280-283, 2009. http://dx.doi.org/10.1126/science.1171999

GALABURDA, A. M.; LOTURCO, J.; RAMUS, F.; FITCH, R. H.; ROSEN, G.D. From genes to behavior in developmental dyslexia. Nat Neurosci, v. 9, n. 10, p. 1213-1217, 2006. http:// dx.doi.org/10.1038/nn1772

GALABURDA, A. M.; MENARD, M. T.; ROSEN, G. D. Evidence for aberrant auditory anatomy in developmental dyslexia. Proc Natl Acad Sci USA, v. 91 n. 17, p. 8010-8013, 1994. http://dx.doi. org/10.1073/pnas.91.17.8010 
GALLABURDA, A. M.; LIVINGSTONE, M. Evidence for magnocellular deficit in developmental dyslexia. In: TALLAL, P.; GALABURDA, A. M.; R. LLINAS, R.; von EULER, C. (Ed.). Temporal information processing in the nervous system: special reference to dyslexia and dysphasia. New York: New York Academy of Sciences. 1993. p. 70-82.

KUJALA, T.; KARMA, K.; CEPONIENE, R.; BELITZ, S.; TURKKILA, P.; TERVANIEMI, M.; NAATANEN, R. Plastic neural changes and reading improvement caused by audiovisual training in reading-impaired children. Proc Natl Acad Sci USA, v. 98 , n. 18, p. 10509-10514, 2001. http://dx.doi.org/10.1073/pnas. 181589198

LIBERMAN, I. Y.; SHANKWEILER, D.; ORLANDO, C.; HARRIS, K. S.; BERTI, F. B. Letter confusions and reversals of sequence in the beginning reader: implications for Orton's theory of developmental dyslexia. Cortex, v. 7, n. 2, p. 127-142, 1971. http://dx.doi.org/10.1016/S0010-9452(71)80009-6

MASSI, G. A Dislexia em questão. São Paulo: Lexus, 2007.

MCCRORY, E. J.; MECHELLI, A.; FRITH, U.; PRICE, C. J. More than words: a common neural basis for reading and naming deficits in developmental dyslexia? Brain, v. 128, pt 2, p. 261-267, 2005.

MURPHY, C. F. B.; SCHOCHAT, E. Correlações entre leitura, consciência fonológica e processamento temporal auditivo. Pró-Fono - Revista de Atualização Científica, v. 21, n. 1, p. 13-18, jan.-mar. 2009

MUSZKAT, M.; RIZZUTTI, S. O professor e a dislexia. São Paulo: Cortez, 2012.

NICOLSON, R. I.; FAWCETT, A. J.; DEAN, P. Developmental dyslexia: the cerebellar deficit hypothesis. Trends Neurosci, v. 24, n. 9, p. 508-511, 2001. http://dx.doi.org/10.1016/S01662236(00)01896-8

PAULESU, E.; DEMONET, J. F.; FAZIO, F.; MCCRORY, E.; CHANOINE, V.; BRUNSWICK, N.; CAPPA, S. F.; COSSU, G.; HABIB, M.; FRITH, C. D.; FRITH, U. Dyslexia: cultural diversity and biological unity. Science, v. 291, n. 5511, p. 2165-2167, 2001. http://dx.doi.org/10.1126/science.1057179

PEREIRA, V. W.; SCLIAR-CABRAL, L. Compreensão de textos e consciência textual: caminhos para o ensino nos anos iniciais. Florianópolis: Insular, 2012.

RAMUS, E.; ROSEN, S.; DAKIN, S.C.; DAY, B. L.; CASTELLOTE, J. M.; WHITE, S.; FRITH, U. Theories of developmental dyslexia: insights from a multiple case study of dyslexic adults. Brain, v. 126 , pt 4, p. $841-865$, 2003. http://dx.doi.org/10.1093/brain/ awg076

RAMUS, F. Developmental dyslexia: specific phonological deficit or general sensorimotor dysfunction? Curr Opin Neurobiol, v. 13 , n. 2 , p. 212-218, 2003. http://dx.doi.org/10.1016/S09594388(03)00035-7

RYAN, M. The Other Sixteen Hours: The Social and Emotional Problems of Dyslexia (Orton Emeritus Series). Baltimore: International Dyslexia Association. 2000.

SAUER, L.; PEREIRA, L. D.; CIASCA, S. M.; PESTIN, M.; GUERREIRO, M. Processamento auditivo e SPECT em crianças com dislexia. Arq. Neuro-Psiquiatria, v. 64, n. 1, mar. 2006.
SHAYWITZ, B. A.; SHAYWITZ, S. E.; PUGH, K. R.; MENCL, W. E.; FULBRIGHT, R. K.; SKUDLARSKI, P.; CONSTABLE, R. T.; MARCHIONE, K. E.; FLETCHER, J. M.; LYON, G. R.; GORE, J. Disruption of posterior brain systems for reading in children with developmental dyslexia. Boil Psychiatry, v. 52, n. 2, p. 101-110, 2002. http://dx.doi.org/10.1016/S0006-3223 (02)01365-3

SHOCHAT, E.; BORGES, M. C. F. Processamento auditivo em crianças com transtorno de leitura. Universidade de São Paulo, 2004.

SILANI, G.; FRITH, U.; DEMONET, J. E.; FAZIO, F.; PERANI, D.; PRICE, C.; FRITH, C. D.; PAULESU, E. Brain abnormalities underlying altered activation in dyslexia: a voxel based morphometry study. Brain, v. 128, pt 10, p. 2453-2461, 2005. http://dx.doi.org/10.1093/brain/awh579

SILVA, C.; CAPELlinI, S. Programa de remediação fonológica: proposta de intervenção fonológica para Dislexia e transtornos de aprendizagem. São José dos Campos, SP: Pulso Editorial, 2011.

SNOWLING, M. J.; HULME, C. (Ed.). The Science of reading: a handbook. Oxford: Blackwell, 2005.

STEIN, J. The magnocellular theory of developmental dyslexia. Dyslexia, v. 7, n. 1, p. 12-36, 2001. http://dx.doi.org/10.1002/ dys. 186

TEIXEIRA, S.; MARTINS, S. Dislexia na educação infantil: intervenção com jogos, brinquedos e brincadeiras. 2. ed. Rio de Janeiro: Wak, 2014.

TEMPLE, E.; POLDRACK, R. A.; PROTOPAPAS, A.; NAGARAJAN, S.; SALZ, T.; TALLAL, P.; MERZENICH, M. M.; GABRIELI, J.D. Disruption of the neural response to rapid acoustic stimuli in dyslexia: Evidence from functional MRI. Proc. Natl Acad Sci USA, v. 97, n. 25, p. 13907-13912, 2000. http://dx.doi. org/10.1073/pnas.240461697

TORGESEN, J. K. Recent discoveries on remedial interventions for children with dyslexia. In: SNOWLING, M. J.; HULME, C. (Ed.), The Science of reading: a handbook. Oxford: Blackwell, 2005. p. 521-537. http://dx.doi.org/10.1002/9780470757642.ch27

VALDOIS, S.; BOSSE, M. L.; TAINTURIER, M. J. The cognitive deficits responsible dor developmental dyslexia review of evidence for a selective visual atencional disorder. Dyslexia, v. 10, n. 4, p. 339-363, 2004. http://dx.doi.org/10.1002/dys.284

VELLUTINO, F. R.; FLETCHER, J. M.; SNOWLING, M. J.; SCANLON, D. M.. Specific reading disability (dyslexia): what have we learned in the past four decades? J Child Psychol Psychiatry, v. 45, n. 1, p. 2-40, 2004. http://dx.doi.org/10.1046/j.0021-9630. 2003.00305.x

ZOCCOLOTTI, P.; DE LUCCA, M.; DI PACE, E.; GASPERINI, F.; JUDICA, A.; SPINELLI, D. Word length effect in early reading and in developmental dyslexia. Brain Lang, v. 93, n. 3, p. 369-373, 2005. http://dx.doi.org/10.1016/j.bandl.2004.10.010

Recebido: 30 de agosto de 2014

Aprovado: 14 de novembro de 2014

Contatos:roneiguaresi@uesb.edu.br catianejq@bol.com.br marciamangueira@hotmail.com.br 